\title{
Das Unheimliche e o ato criativo: algumas considerações
}

\section{Samara de Oliveira Lima ${ }^{1}$}

Resumo: No presente estudo visei estabelecer relações entre a arte e a psicanálise por meio do conceito de Sigmund Freud, das Unheimlichee. A arte conceitual é aqui destacada como objeto de investigação, em um contexto de uma pesquisa bibliográfica classificada como exploratória. Apresento, portanto, uma relação entre o ato criativo e o texto O inquietante (1919), de Sigmund Freud, a partir do qual trabalhei a questão da alteridade, entendida como uma categoria do fenômeno que melhor elabora o "estranho-familiar" que reside em nós mesmos.

Palavras-chave: Ato criativo; Psicanálise; das Unheimliche; Arte conceitual.

\section{Das Unheimliche and creative act: some considerations}

Abstract: In this study I aimed to establish relations between art and psychoanalysis through the concept of Sigmund Freud, from das Unheimlichee. Alterity is highlighted here as an object of investigation, in a context of conducting a bibliographic research classified as exploratory. I present a relation between the creative act and the text Sigmund Freud's The Disquieting (1919), from which I worked the question of alterity, understood as a category of the phenomenon that best elaborates the "strange-familiar" that resides in ourselves.

Keywords: Creative act; Psychoanalysis; from Unheimlichee; Conceptual art.

1 Psicóloga, Psicanalista, Professora e fotógrafa. Mestre em Comunicação, linguagens e Cultura. Especialista em Psicologia Clínica e em Desenvolvimento Infantil. Supervisora do Estágio obrigatório em Psicologia clínica, abordagem Psicanalítica, da faculdade Maurício de Nassau, professora da pós-graduação em Políticas Públicas para mulheres na Amazônia. Pesquisadora das relações entre, Arte e psicanálise, desenvolve e coordena o projeto Nômades retratos, sobre fotografia e psicologia. Vínculo institucional: Universidade da Amazônia (PPGCLC/ UNAMA).E-mail: samilima@gmail.com. ORCID: https://orcid.org/0000-0001-8015-3311. Lattes iD: http://lattes. cnpq.br/7411764564125760 


\section{CONSIDERAÇÕES INICIAIS}

Albert Camus (1913-1960), grande ficcionista do século XX, escreveu por volta de 1942 o livro intitulado O Estrangeiro, no qual, usa como fonte para redigi-lo o texto O Estranho (1919) da obra freudiana, criando paralelos entre o distanciamento que por vezes nos assola do mundo ao redor. Nesse sentido, a escolha do tema não é aleatória, e representa exatamente o distanciamento existente dentro de nós mesmos, que acaba relevando, também, a relação com o outro externo e vice-versa.

Assim sendo, faço um convite a esse outro olhar para uma produção acadêmica, na qual a metalinguagem é predominante. Portanto, para compreender o texto a seguir, é necessário senti-lo, absorvê-lo. Portanto, peço que, ao lê-lo, abra sua criatividade e um olhar 'outro'.

Com relação ao texto, esclareço desde já, que não mencionarei a aplicação da teoria freudiana do inconsciente para fins de análises de casos. Não é esse o interesse aqui. Trago outras questões para o debate. Apresento uma análise crítica sobre questões que envolvem arte e psicanálise, buscando chegar a algumas sugestões as quais podem, inclusive, contribuir para uma análise crítica de ambas.

Para tanto, intencionei demonstrar como o conceito de estranho-familiar (1919) - das Unheimlichee - intitulado e definido por Sigmund Freud (1856-1939) pode acrescentar às discussões sobre os dois campos: da arte e da psicanálise, por isso busquei investigar possíveis relações entre Unheimliche e o processo criativo.

Por fim, abri janelas e não fechei conclusões, parti, somente, para uma instigação de conquistar mais envolvimento entre a relação arte e a psicanálise, abordando o papel da arte conceitual contemporânea e suas inúmeras interlocuções com a sociedade, incluindo a análise das subjetividades e identidades desta sociedade.

Neste trabalho utilizei uma pesquisa bibliográfica, assim identificada quanto ao delineamento adotado, é classificada como exploratória, nos termos descritos por Gil (2002, p. 41), tendo em vista o objetivo principal de "aprimoramento de ideias ou a descoberta de intuições". Dito de outra forma, busquei uma aproximação entre temas, proporcionando maior familiaridade com as questões investigadas.

A flexibilidade no planejamento pretendeu possibilitar "a consideração dos 
mais variados aspectos relativos ao fato estudado". Justifica-se, assim, tanto a proposta de levantamento bibliográfico, quanto de análise de exemplos que "estimulem a compreensão" (SELLTIZ et al, 1967, p. 63, apud GIL, p. 41). Dentre as fontes bibliográficas estudadas destaca-se o livro $O$ Inquietante (FREUD, 1919), assim escolhido para fundamentar a aproximação entre ato criativo e alteridade.

Este estudo não busca se fechar em si, pelo contrário, o seu grande objetivo é a abertura, abertura ao novo, ao desconhecido, seja nos próprios conceitos utilizados, seja na maneira de se escrever ou de se fazer pesquisa, principalmente em virtude da utilização do método artístico da colagem ou fotomontagem, em que sobreposições de imagens criam uma forma. Uma forma feita de vários pedaços que, unidos, criam um todo, portanto uma outra forma de escrita acadêmica, distinta da escrita convencional.

Desse modo me pergunto: por que o deslocamento de um determinado objeto, fora de seu contexto funcional, criação muito utilizada na arte conceitual, faz emergir um certo estranhamento? E mais, este estranhamento é, então, a base necessária para que se efetue um processo de criação, já que a potência interpretativa é elevada? Em outras palavras, a liberdade de interpretação, ou como Freud nos conta, a associação livre é potencializada nestes casos?

Interessa-me relacionar a arte conceitual/contemporânea ao texto escrito por Freud que mais se aproxima, a meu ver, da potência criativa. $O$ texto $O$ inquietante traz temas do mistério para elucidar questões do inconsciente, como os textos literários de E. T. A. Hoffman (1776-1822), grande escritor de contos fantásticos dos séculos XVIII e XIX, dos quais se destaca $O$ homem da areia (1816), o qual Freud analisa e traça todo um percurso das neuroses infantis que acabam culminando em surtos do personagem principal, realizando um paralelo entre os contos fantásticos, escritos neste texto de Hoffman e as paranoias.

De maneira geral, essas figuras fantásticas do imaginário, sejam literárias ou artísticas, servem para provar que existe sentido, no que parece não ter, algo de enigmático no que parece evidente, uma carga de pensamento no que parece irracional.

Resumidamente, as figuras que surgem neste texto de Freud não são materiais com o qual a interpretação psicanalítica prova sua capacidade de interpretar as formações da cultura, elas são, na verdade, testemunhas da existência de certa relação do pensamento com o não pensamento. 
Direi de outra forma: a psicanálise ou a teoria analítica do inconsciente só é possível porque já existe, fora do terreno propriamente clínico, uma certa identificação com uma forma inconsciente do pensamento e, no terreno das artes, se define como o âmbito de efetivação privilegiada desse inconsciente. Meu arcabouço filosófico é em cima disto: ancorado na teoria freudiana dessa configuração já existente do pensamento inconsciente que se desenvolveu de modo predominante no terreno da estética, "tratar-se-á de pensar os estudos 'estéticos' de Freud como marcas de uma inscrição do pensamento analítico da interpretação no horizonte do pensamento estético" (RANCIÈRE, 2009, p. 11).

Sempre lembrando que a ideia de estética aqui utilizada não se resume a 'ciência' ou disciplina da arte e sim das consequências que a arte provoca, ou melhor dizendo, o que o processo de criação suscita em seus participantes. Estética aqui designa o domínio do conhecimento do sensível, do pensamento que se opõe à lógica. Portanto, estética designa um tipo de julgamento e não de domínio sobre o objeto; estética não é um novo modo de designar o domínio da arte, é uma configuração específica deste domínio.

Dito de outro modo, a estética é quase uma senha para entender o fazer artístico e não é o não pensar é o pensar de forma-outra e aqui, mais uma vez, o texto escolhido como base teórica desta pesquisa se enquadra perfeitamente, visto o seu tratamento e ligação com questões do outro, da alteridade, do estranhamento, do 'inquietante outro' que reside em nós mesmos.

Assim, também, é a ideia que marca uma transformação no pensamento da arte ou do fazer artístico, a entrada do outro na cena artística ou no processo criativo, principalmente a partir do manifesto Dadaísta, escrito por Hugo Ball em 1916, em plena primeira guerra mundial. O movimento Dada se dizia um movimento de protesto, não somente político, como também no modo de se fazer e pensar arte. (Re)Tirando a arte de um lugar 'especial' e trazendo-a para o cotidiano da sociedade, criticando o fazer artístico, assim como se critica a própria sociedade. Este novo regime de se fazer arte é o lugar onde se constitui uma ideia específica do pensamento.

Ao sair de uma forma lógica cartesiana do pensamento se dá abertura para um outro olhar. Abre-se para uma liberdade criativa e para a associação livre do pensamento inconsciente, possibilitando a emergência de toda uma potência criativa. 
Diante disso, resolvi utilizar o deslocamento de objeto que a arte conceitual realiza, introduzindo um certo incômodo nessa lógica cartesiana, o que nos obriga a entrar neste outro pensamento ou pensamento outro, como preferirem. Portanto, o pensamento freudiano do inconsciente só é possível com base nesse regime de pensamento da arte: "o pensamento freudiano, para além de qualquer classicismo das referências artísticas de Freud, só se torna possível com base na revolução que opera a passagem do domínio das artes do reino da poética para o da estética" (RANCIERE, 2009, p. 14).

\title{
AS PRIMEIRAS COLAGENS
}

Inicio esta sessão com uma citação da psicanalista Suely Rolnik, onde você já pode perceber com quais conceitos criei este artigo:

\begin{abstract}
Temos que nos livrar das pegadas da cilada romântica que alia a criação à dor. Qualquer situação em que a vida se vê constrangida pelas formas da realidade e/ou o modo de descrevê-las produz estranhamento. Segue-se um desconforto que mobiliza a necessidade de expressar o que não cabe no mapa vigente, com a criação de novos sentidos, condição para que a vida volte a fluir. É nisso que consiste a experiência estética do mundo: ela depende da capacidade do corpo de fazer-se vulnerável a seu entorno, deixando-se tomar pela sensação da disparidade entre as formas da realidade e os movimentos que se agitam sob sua suposta estabilidade, o que coloca o corpo em 'estado de arte'. É uma espécie de experiência do mundo que vai além do exercício de sua apreensão reduzida às formas, operado pela percepção e sua associação a certas representações, a partir das quais Ihes atribui sentido (ROLNIK, 2002, p.02).
\end{abstract}

Dessa maneira, entende-se que a experiência estética passa a não ser uma atividade do pensar lógico cartesiano, mas muito mais relacionada às sensibilidades, ou seja, com as experiências do sentir. No texto $O$ inquietante, Freud nos conta que "a estética não é limitada à teoria do belo, mas definida como teoria das qualidades de nosso sentir" (FREUD, 1919, p. 329).

Trabalhei, portanto, com a ideia de que a arte conceitual se distingue dos movimentos artísticos anteriores pela experiência estética ligada ao sentir, no âmbito das reflexões perceptivas que ela suscita, muito mais do que pela pura apreciação e contemplação da obra artística e aqui neste ponto, está diretamente relacionada ao que Freud (1919) destacou nos seus estudos sobre estética.

Pensei, assim, nos pontos de interação entre os personagens envolvidos, nos termos da dinâmica das relações entre estes, enquanto processo cria- 
tivo; para isso é necessário colocar em jogo as peças, ou seja, os conceitos. Primeiramente, vou tentar compreender o que seja contemporâneo, sua forma de fazer arte, assim como a maneira que esta sociedade contemporânea executa seu fazer artístico e como institui o que é arte.

Freud (1919) nos coloca a seguinte situação sobre o fenômeno literário, que pode ser estendido à(s) arte(s) como um todo:

É evidente que essas considerações não esgotam o tema das liberdades do escritor e dos privilégios da ficção em evocar ou inibir a sensação do inquietante. Diante do vivenciado nos comportamos, em geral, de maneira uniformemente passiva, sucumbindo à influência do que sucede. Mas em relação ao escritor somos particularmente maleáveis; por meio do estado de ânimo em que nos coloca, das expectativas em que nós suscita, ele pode desviar nossos processos afetivos de uma direção e orientá-los para outra, e pode frequentemente obter, do mesmo material, efeitos bem diversos. Tudo isso é conhecido há bastante tempo e provavelmente foi examinado pelos especialistas em estética (FREUD, 1919, p. 374).

Dito isso, penso em um movimento que se contrapõe à dicotomia artista - espectador, na qual um seria mais ativo e o outro, um tanto passivo sem muito espaço para a abertura que o processo possa oferecer diante dos encontros, a convergência de olhares ou seu distanciamento. Sendo assim, o que a arte contemporânea, principalmente aquela ligada ao movimento conceitual ou conceitualismo, das décadas de 1960 e 1970, traz à tona são questões sobre o encontro entre artista e espectador, sobre a diferença, entendida como não identidade. Como cita Frayze-Pereira (2005, p. 20):

E, com efeito, essa noção de diferença aponta para o caráter não-puro do sentir, para o aspecto ambíguo das experiências artísticas contemporâneas, insólitas e perturbadoras, ambivalentes e excessivas, irredutíveis à identidade, entretecidas na existência de homens e mulheres da segunda metade do século XX. De resto, é exatamente nesse tipo de sensibilidade, que mantém relações de vizinhança com os estados psicopatológicos, com as toxicomanias e as perversões, com as culturas primitivas e as práticas sociais alternativas, que as artes, a literatura e a música contemporânea encontraram a sua inspiração.

Falar sobre arte contemporânea é tratar, sobretudo, de conceitos, de questões sociais e políticas, sobre o não tradicional, sobre o fazer artístico não institucionalizado. É, portanto, também a estranheza - no sentido da diferença - de fazer, inclusive do próprio corpo, objeto artístico, como trata a performance e a body art.

Este mo(vi)mento na arte ainda traz consigo muitas brechas, mas é delas que emergem novas discussões sobre o poder artístico na atualidade, ou 
sua função na sociedade contemporânea. Não são todos que concordam com este tipo de fazer artístico. Muitos ainda preferem o tradicionalismo, a arte em museus, os leilões milionários. Porém, ao negar um movimento mais conceitual, nega-se também a possibilidade de enxergar a arte ( $\mathrm{e}$ a própria vida) com outros olhos ou, melhor dizendo, com um olhar outro para este fazer, rico em potência criativa.

Trouxe para este trabalho alguns destes autores, como João Frayze-Pereira, Edson Sousa e Suely Rolnik. Mas absorvi intelectualmente as influências de O Inquietante de Freud (1919) para que me oferecesse arcabouço psicanalítico-teórico, compreendendo melhor o conceito de alteridade, de deslocamento, do contato com o(s) outro(s) no ato criativo.

"Os autores que trataram dessa questão são muitos, de extrações diversas - da Filosofia à Psicanálise, da Antropologia à Literatura - e em todos a questão do corpo ocupa lugar privilegiado" (FRAYZE, 2004, p. 20).

\section{ARTICULAÇÕES CONCEITUAIS}

Nesta seção estão presentes os principais conceitos que utilizei neste estudo, assim como as articulações que nele pretendi realizar. Com isso, da mesma forma que a maioria dos artistas escolhe seus materiais previamente, aqui também selecionei o arcabouço teórico, representado por conceitos, tomados como ferramentas para a presente reflexão, dispositivos para a discussão aqui proposta.

Neste artigo refiro-me a questões sobre a alteridade, portanto é importante conceituar o que vem a ser esta ideia de alteridade, tão difundida ultimamente, principalmente entre a ala mais progressista da sociedade, mas por vezes erroneamente utilizada e compreendida. Alteridade, no sentido mais literal da palavra, significa o que é outro ou diferente.

Na história das culturas, a alteridade é fundamental para a manutenção da sociedade, visto que, ao saber lidar com o outro ou diferente, se tem uma maior possibilidade de continuidade de uma comunidade, caso contrário não existiria, por exemplo, o pacto civilizatório, no qual a tolerância ao outro é fundamental. Nas questões concernentes à Psicanálise, a alteridade se caracteriza como o próprio inconsciente, como nos diz SOUZA (2015, p. 76) em sua tese de doutorado "a qualificação do inconsciente como um estrangeiro tão próximo em terrenos da vida mental". 
Na teoria psicanalítica, o texto que melhor trabalha a questão da alteridade é um dos últimos de Sigmund Freud, de 1919, nomeado O Estranho ou $O$ inquietante (estes termos se modificam de acordo com a tradução). Curiosamente este texto recebeu mais atenção nos campos da linguística, da arte e da filosofia do que no próprio campo psicanalítico.

Destaco, aqui, dois processos através dos quais se apontam exemplos desta alteridade, neste texto apontada - processos analítico e criativo -, ambos como possibilidades de sublimes-ações. Segundo Birman (2002, p. 123), "pela ação sublime ou pela sublimação o mundo seria recriado novamente pela subjetividade, que trabalharia as coisas presentes no real numa direção possível, anunciando ainda com isso novas formas de satisfação".

Sublimar, de acordo com Birman (2002), seria um ato de ruptura, já que os circuitos pulsionais marcados por fixações e repetições seriam substituídos por outras possíveis satisfações. Ainda nas correspondências com Fliess, Freud admite a sublimação um caráter opositor à sexualidade, ou seja, de defesa contra os fantasmas da sexualização humana. "É uma operação de 'refinamento' psíquico - criando as grandes produções do espírito - pelo qual a defesa afastaria a presença brutal de fantasmas sexuais" (BIRMAN, 2002, p. 101).

Retornando aos conceitos principais do texto, destaco a necessidade de conceituar o que chamo de criação ou ato criativo. BELLOC (2005) define a criação como a produção de uma imagem nova, sendo que este processo está diretamente relacionado à possibilidade de estabelecimento de laços cúmplices.

Quando nos deparamos com processos criativos nas artes, estes laços, ou cumplicidade, caracterizam-se pelo diálogo entre produtor e obra e entre observador e obra. Neste sentido, observador, ou consumidor, é o ouvinte, o leitor, o público, o espectador, aquele que dá sentido ao que foi criado, e produtor é aquele que executa a obra. Já a definição de obra é mais abrangente e depende justamente da posição em que cada um, observador e produtor, se encontra em determinado instante.

Para o produtor, a obra é algo do nível da realização; para o consumidor, é algo ligado à valorização, ou o que Marcel Duchamp, no texto O Ato Criador, de 1957, trabalho apresentado à convenção da Federação Americana de Artes, em Houston, Texas, chama de fenômeno de transmutação, instaurando a partir de então uma Nova Arte, em que afirma que possa existir a transformação da matéria ou de qualquer objeto em uma obra de arte. 
Disto isto, obra é aquilo que é produzido pelo produtor e posteriormente interpretado pelo consumidor, culminando, com isso, no próprio processo de criação. Portanto, a criação não é apenas uma ação do produtor/artista, o consumidor/público estabelece uma conexão entre a obra, com suas qualidades intrínsecas, e o mundo exterior, dando-lhe a possibilidade de ser interpretada e decifrada.

Dentro deste prisma, Valéry (1938, apud BELLOC, 2005, p. 6), explica que:

Produtor e consumidor são dois sistemas essencialmente separados. A obra para um é o termo; para outro, a origem de desenvolvimentos que podem ser tão estranhos entre si quanto quisermos [...]. Podemos considerar apenas a relação da obra com seu produtor, ou a relação da obra com aquele que é modificado por ela, uma vez pronta. A ação do primeiro e a reação do segundo nunca podem ser confundidas. As ideias que ambos fazem da obra são incompatíveis.

\section{A inquietante estranheza de ser.}

"O homem que diz "dou" não dá, porque quem dá mesmo não diz

O homem que diz "vou" não vai, porque quando foi já não quis

O homem que diz "sou" não é, porque quem é mesmo é "não sou"

O homem que diz "tô" não tá, porque ninguém tá quando quer ..."Parte superior do formulárioParte inferior do formulário

(Composição: Baden Powell / Vinícius de Moraes)

No pequeno trecho de música acima, Canto de Ossanha, os autores Vinícius de Moraes e Baden Powell, retratam a inconsistência da "sabedoria" racional ou aquilo que é inconsciente para o homem, visto que, segundo a letra, "o homem que diz sou, não é, porque quem é mesmo é não sou". É como se um outro entrasse em cena e lhe tomasse a razão, como se o homem fosse justamente onde não é. É dessa forma que Souza (2015, p. 76) qualifica o inconsciente, "como um estrangeiro tão próximo em terrenos da vida mental".

O posto-chave que almejei neste artigo foi discutir a alteridade na arte, ou melhor, no processo de criação utilizando o conceito de Unheimliche de Sigmund Freud como base teórico-filosófica de tal conceituação. Esse pode ser um ponto inovador deste texto, visto que poucos artigos ou pesquisas acadêmicas refletem sobre o diálogo entre o processo criativo e $O$ Inquietante (1919). Dentre os trabalhos que hoje investigam articulações entre arte e psicanálise destacam-se algumas coletâneas, como Psicanálise, Arte e Estéticas de Subjetivação, organizada por Elida Tessler e Abrão Slavutzky (2001); Giovanna Bartucci (2002), A invenção da Vida - Arte 
e Psicanálise, organizada por Edson Sousa, e Sobre Arte e Psicanálise, sob organização de Tania Rivera e Vladimir Safatle (2006).

Acredito que um artigo se constrói semelhante à criação de uma obra, já que, de acordo com Rolnik (2002, p. 372), em seu texto sobre a artista plástica Lygia Clark, "a obra se completa quando um sentido é concebido pelo espectador a partir das sensações mobilizadas por este encontro em sua subjetividade".

Em se tratando da arte, de acordo com Rolnik (2002, p. 371):

\begin{abstract}
A arte participa da decifração dos signos das mutações sensíveis, inventando formas através das quais tais signos ganham visibilidade e integram-se ao mapa vigente. A arte é, portanto, uma prática de experimentação que participa da transformação do mundo. Fica, então, mais explícito que a arte não se reduz ao objeto que resulta de sua prática, mas ela é essa prática como um todo: prática estética que abraça a vida como potência de criação em diferentes meios onde ela opera.
\end{abstract}

Alguns termos que são aqui discutidos e conceituados, partem do pressuposto de que o ato criativo está ligado a uma certa estranheza presente no processo. O texto O Estranho, de Sigmund Freud foi escrito entre os anos de 1917 e 1920, ou seja, em meio às turbulências da primeira guerra mundial e a toda estranheza que a guerra traz. Conforme Freud (1919, p. 341-350):

\begin{abstract}
Um dos mais seguros artifícios para criar efeitos inquietantes ao contar uma história', escreve Jentsch, 'consiste em deixar o leitor na incerteza de que determinada figura seja uma pessoa ou um autômato, e isso de modo que tal incerteza não ocupe o centro da sua atenção, para que ele não seja induzido a investigar a questão e esclarecê-la, pois assim desapareceria o peculiar efeito emocional, como foi dito. Em seus contos fantásticos, E.T.A. Hoffmann valeu se dessa manobra psicológica repetidamente e com sucesso'. [...] E.T.A Hoffmann é o inigualável mestre do inquietante na literatura. Seu romance $\mathrm{O}$ elixir do diabo traz todo uma série de temas a que se pode atribuir o efeito inquietante da história ... no final, quando o leitor é informado dos pressupostos da ação, que até então lhe foram ocultados, o que daí resulta não é o esclarecimento, mas uma total perplexidade para o leitor ... Temos de contentarmo-nos em extrair os mais notáveis entre os temas de efeito inquietante, para investigar se também eles podem ser derivados de fontes infantis.
\end{abstract}

É importante ressaltar que esta citação tem uma forte relação com o conceito de ato criativo que estou utilizando, visto ser justamente na experiência artística que se suscita esta inquietação outra, seja literária, plástica, performática, sendo intencional ou não, em que reside nossa questão.

De acordo com Freud (1919, p. 329), “o psicanalista trabalha em outras 
camadas da vida psíquica, e pouco lida com as emoções atenuadas, inibidas quanto à meta, dependentes de muitos fatores concomitantes, que geralmente constituem o material da estética".

Contudo, quando o psicanalista se inclina a este tipo de investigação, já toma consciência de que será um trabalho de certa forma negligenciado pela literatura especializada. O Estranho (1919) faz parte de um destes textos que, de certa forma, é marginalizado por uma grande parte dos psicanalistas.

O inquietante é um destes domínios. Sem dúvida, relaciona-se ao que é terrível, ao que desperta angústia e horror, e também está claro que o termo não é usado sempre num sentido bem determinado, de modo que geralmente equivale ao angustiante (FREUD, 1919, p. 329).

Em um momento do texto, Freud passa a tentar compreender melhor os termos inquietante e angustiante, ou seja, tenta encontrar um núcleo comum entre os dois conceitos, buscando, no interior da angústia, o que inquieta e porquê. Em um trabalho sobre estética, pesquisado por Freud, este afirma que nada encontrou sobre essas condições repulsivas e angustiantes das sensibilidades, tendo a maioria dos olhares dos pesquisadores de estética sido voltado ao belo e sensações confortantes que a arte traz:

A respeito disso nada encontramos nos minuciosos tratados de estética, que se ocupam antes das belas, sublimes, atraentes - ou seja, positivas - sensibilidades, de suas condições e dos objetos que as provocam, do que aquelas contrárias, repulsivas, dolorosas (FREUD, 1919, p. 330).

Na verdade, este sentimento ou sensação angustiante varia de pessoa para pessoa, parecendo haver uma suscetibilidade para o inquietante. A partir deste ponto do texto, Freud passará a traçar uma etimologia da palavra inquietante ou estranhamento em alemão, chegando a pensar em dois caminhos, um sobre a evolução do termo Unheimliche e o outro reunindo tudo que causa estranheza em nós. Portanto, de acordo com ele:

Podemos encetar dois caminhos agora: explorar que significado a evolução da língua depositou na palavra unheimliche, ou reunir tudo aquilo que, nas pessoas e coisas, impressões de sentidos, vivências e situações, desperta em nós o sentimento do inquietante, inferindo o caráter velado do inquietante a partir do que for comum a todos os casos (FREUD, 1919, p. 331).

Os dois caminhos resultam no mesmo conceito de inquietante, o de que ele é aquela coisa assustadora que remonta ao que é muito familiar. Mas 
Freud também traz uma outra questão: como é possível que algo tão familiar se torne inquietante? E por quê? Essas serão as principais indagações que nortearão este texto de 1919.

Acredito que estas inflexões se fizeram necessárias para abrir o caminho do pensamento em direção às relações entre a alteridade e ao ato criativo. Acredito que Freud contribui significativamente para alinhar o construto em torno do que é o inquietante. $\mathrm{O}$ eu acaba se descobrindo um outro, um outro desconhecido a se desvendar; e é através da relação com o outro externo que muitas vezes desvendamos nossas relações com o outro interno, afinal somos o ser do espelho, mas não o espelho físico e sim o espelho do outro. Já que é através do olhar do outro que a gente se vê.

\section{POSSÍVEIS CONCLUSÕES}

Ao largo da escrita deste artigo fui encontrando elos entre um conceito e outro, entre uma ideia e outra, e nessa cadeia intermitente de teorias e conceitos sobre arte e psicanálise cheguei a algumas possíveis conclusões.

De acordo com o objetivo geral deste artigo, algumas relações foram estabelecidas entre arte e psicanálise por meio do conceito de Sigmund Freud, das Unheimlichee, com destaque para papel do "outro" ou a alteridade.

Verifiquei contribuições do texto O Inquietante (FREUD, 1919), para 0 ato criativo na arte conceitual, no sentido em que este pode revelar uma sensação inquietante-familiar, trabalhando assim a tríade: castração, onipotência e retorno do recalcado, este último sendo o próprio sintoma psicanalítico, ou seja, ao se deparar com a sensação inquietante podemos nos deparar com o familiar, aquilo que foi um dia recalcado.

Fica fortalecida a ideia de que, para ocorrer um ato criativo, há de acontecer algo novo; ou seja, a criação nos leva ao novo, este novo nos remete ao desconhecido e o desconhecido, ao diferente, ao outro, a alteridade.

Em linhas gerais, a obra freudiana analisada neste artigo tem muito a contribuir quando falamos em alteridade criativa. É como se existisse um outro em nós mesmos, que no ato criativo aparecesse através de 
uma sensação de inquietude estranha, nos convidando de certa forma a entrar em contato com este estranho-familiar - Unheimliche. A alteridade criativa tem esta capacidade. $\mathrm{E}$ talvez seja isso que a arte conceitual revela.

Este estudo destacou, portanto, que no ato criativo, um outro que é inquietante, também é familiar, e que funciona como uma categoria do fenômeno artístico, visto que, ao entrar em contato com algumas situações, sentimos essa estranheza que nos tira do lugar. Como enuncia Edson Sousa (2006, p. 46), "por um instante, o ato de criação desorganiza uma determinada série, instaurando outro pensamento possível, uma outra imagem possível".

Abordei neste artigo as interfaces do ato criativo e a partir dele, como dito no início, uma fotocolagem de conceitos, em que o inconsciente Freudiano nos transporta a uma questão relevante sobre o outro, a alteridade, de modo que a própria noção de memória também é revisitada, "passa por uma ressignificação, pois ela se distancia da percepção consciente para ter relação com os registros inconscientes" (REA, 2015, p.653).

Com isso, concluo que existem inúmeras proximidades entre processo criativo e o texto $O$ inquietante (1919), e ainda, que muitas possibilidades de inovação são possíveis e que abrem pensamentos outros, trazendo mais discussões, para este campo, atravessadas pelas relações entre arte e psicanálise, de maneira a tê-las sempre como críticas de uma sociedade.

Portanto, neste artigo não fecho conclusões sobre o real alcance das relações entre a arte e psicanálise - pelo contrário, abro "janelas" para essas relações, trazendo inúmeras possibilidades de discussão do fenômeno inquietante de nós mesmos, da alteridade, da potência criativa, todas imersas no que chamamos, hoje, de arte conceitual-contemporânea, aquela que discute a própria arte e seu papel sociocultural, aquela que implica o outro no processo. É como Sousa (2006, p. 45) indica em seu texto Monocromos Psíquicos: alguns teoremas: "uma espécie de liberdade de confrontar-se com sua imagem correndo o risco de descobrir-se outro". 


\section{REFERÊNCIAS}

BIRMAN, J. Fantasiando sobre a sublime ação. In: Psicanálise, Arte e Estéticas de Subjetivação.

BARTUCCI, G. (org.) Rio de Janeiro: Imago ED.2002.

CAMUS, Albert. O Estrangeiro. Rio de Janeiro: Record, 2004.

DUCHAMP, Marcel. O ato criador. IN: BATTOCK, G. A Nova Arte. $2^{\text {a }}$ ed. São Paulo: Editora Perspectiva, 2002.

FRAYZE-PEREIRA, J. A. A Dimensão Estética da Experiência do Outro, In: Revista Proposições, v. 15, 2004. No01(43).

FRAYZE-PEREIRA, J. A. Arte, Dor: Inquietudes Entre Estética e Psicanálise. Cotia, SP: Ateliê Editorial, 2005.

FREUD, S. (1919). O Estranho In: Obras Completas. ESB, vol. XIV. São Paulo: Cia das letras, 2010.

( 1926) A Psicanalise In: Obras Completas de Sigmund Freud. Rio de Janeiro: Imago ed., (1925-1926) vol. 20.

(1914) A história do movimento Psicanalítico. In: Obras Completas de Sigmund Freud. Rio de Janeiro: Imago ed., (1914-1916) vol. 14. Arte, Literatura e os Artistas/ Sigmund Freud; tradução Ernani Chaves. Belo Horizonte: Autentica Editora, 2015.

. Três ensaios sobre a sexualidade. In: Obras Completas de Sigmund Freud. Rio de Janeiro: Imago ed., (1905) vol. 07.

GIL, A. C. Como elaborar projetos de pesquisa. São Paulo: Atlas, 2002

ROLNIK, S. Alteridade e cultura arte cura? Lygia Clark no limiar do contemporâneo. In: Psicanálise, Arte e Estéticas de Subjetivação. BARTUCCI, G. (org.) Rio de Janeiro: Imago ED.,2002.

SOUZA, M. R. Experiência do Outro, Estranhamento de Si: Dimensões da Alteridade em Antropologia e Psicanálise. Editora da Universidade de São Paulo, 2015.

SOUSA, E. L. A. Monocromos psíquicos: alguns teoremas. In: Sobre Arte e Psicanálise/ Orgs. Tania Rivera e Vladimir Safatle - São Paulo: Escuta,2006. . Uma estética negativa em Freud. In: A Invenção da Vida: Arte e Psicanálise. Orgs. Edson Luis Andre de Sousa, Elida Tessler e Abrao Slavutzky - Porto Alegre: Artes e Ofícios, 2001.

Recebido em 25 de novembro de 2019 e aceito em 16 de março de 2020.

Este é um artigo publicado em acesso aberto sob uma licença Creative Commons (⿻c) ) EY 